\title{
A Study of Calculus Instructors' Perceptions of Approximation as a Unifying Thread of the First-Year Calculus
}

\author{
Kimberly S. Sofronas ${ }^{1}$ - Thomas C. DeFranco ${ }^{2}$. \\ Hariharan Swaminathan ${ }^{2}$ - Nicholas Gorgievski ${ }^{3}$. \\ Charles Vinsonhaler ${ }^{2}$ - Brianna Wiseman ${ }^{4}$. Samuel Escolas ${ }^{4}$
}

\begin{abstract}
This paper discusses findings from a research study designed to investigate calculus instructors' perceptions of approximation as a central concept and possible unifying thread of the first-year calculus. The study also examines the role approximation plays in participants' self-reported instructional practices. A survey was administered to 279 first-year calculus instructors at higher education institutions throughout the United States. Quantitative and qualitative methods were used to analyze the data gathered. Findings from this research will contribute to what is known about the perceptions and teaching practices of calculus instructors regarding the role of
\end{abstract}

Kimberly S. Sofronas

sofronki@emmanuel.edu

Thomas C. DeFranco

tom.defranco@uconn.edu

Hariharan Swaminathan

Hariharan.swaminathan@uconn.edu

Nicholas Gorgievski

Nick.gorgievski@nichols.edu

Charles Vinsonhaler

vinsonhaler@math.uconn.edu

Brianna Wiseman

wisemanb@emmanuel.edu

Samuel Escolas

escolass@emmanuel.edu

1 Emmanuel College, 400 The Fenway, Boston, MA 02115, USA

2 The University of Connecticut, Storrs, CT, USA

3 Nichols College, Dudley, MA, USA

4 Emmanuel College, Boston, MA, USA 
approximation in first-year calculus courses. Research-based findings related to the role of approximation ideas in the first-year calculus could have implications for first-year calculus curricula.

Keywords Calculus instructors' perceptions - Approximation - Central concept . Unifying thread $\cdot$ Curriculum $\cdot$ Higher education

In recent times the mathematics education community, both on a national and international level, has become increasingly concerned with issues related to the teaching and learning of calculus (Heim et al. 2015; Lang 1999; Rasmussen et al. 2014). For example, the Calculus Concept Inventory [CCI], designed to measure students' basic conceptual comprehension of the foundational ideas of differential calculus (Epstein 2013), has been administered to students enrolled in first-semester calculus courses on an international level (Chai et al. 2015; Epstein 2013). Analysis of the data showed U.S. students enrolled in first-semester calculus courses using traditional instructional approaches made no significant gains in their understanding of the essential calculus concepts measured by CCI pre- and post-testing. Except for China, results from other countries were comparable to those of the U.S., bringing into focus the idea that students' basic conceptual understanding of differential calculus is generally of concern across nations (Epstein 2013).

On the national level, the Mathematical Association of America initiated in 2010 a large-scale study known as Characteristics of Successful Programmes of College Calculus (Bressoud et al. 2013) to better understand the demographics of U.S. students who enroll in calculus and to measure characteristics of calculus courses that may affect student success. Bressoud et al. raised questions about the appropriateness of the calculus curricula in light of their findings that (a) Calculus I is most commonly presented as a first introduction to calculus when more than $25 \%$ of students enrolled at research universities enter with $\mathrm{AP}^{1}$ Calculus Examination scores of 3 or higher; (b) the calculus curriculum designed in the 1950s for engineering and physical science majors has fundamentally remained the same even though two-thirds of those who enroll in Calculus I today plan to major in other areas; and (c) students reported decreased confidence, enjoyment, and motivation to continue studying mathematics upon completion of their first-semester undergraduate calculus courses (Bressoud et al. 2013). Bressoud et al. also conducted a review of widely adopted Calculus I textbooks coupled with a review of current research literature on student understanding of key calculus concepts and found:

...the research on student learning of key ideas of calculus has had little impact on the conceptual focus of Calculus I curriculum or teaching. In fact, several studies have revealed that many students who receive high grades in Calculus I

\footnotetext{
${ }^{1}$ The Advanced Placement (AP) Program began in the U.S. in 1957 and was designed to allow high school students to earn credit for and-or advanced placement in college-level coursework to minimize redundancy in academic programs of study in higher education. The scope of the AP Program has expanded dramatically since its inception. More than 19,000 public and private U.S. high schools offer AP courses today. Colleges have been known to use AP course-taking to identify motivated, high achieving students in their admissions processes (College and The 2015; Klopfenstein and Thomas 2009).
} 
have weak understanding of the course's key concepts, ... [which] questions whether the traditional Calculus I curriculum is preparing any students to use ideas of calculus in future courses in mathematics, engineering, or the sciences ( $p$. 692).

Investigations into the role of approximation in the teaching and learning of calculus have gained momentum over the past decade (Martin 2013; Oehrtman 2004, 2008, 2009; Oehrtman et al. 2008, 2014; Oerhtman and Martin 2015; Sealey 2014; Swinyard 2011); however, calls to bring approximation concepts to the fore of first-year calculus curricula are not new (Rietz 1919). Gordon (1993) argued for an early introduction to the approximation of functions, recognizing the local linearity of functions as one of the underlying ideas of the calculus. Further, he identified the approximation of functions as one of the most significant ideas in mathematics and called for it to be more central in first-year calculus courses.

Likewise, reform efforts in the 1980s and 1990s advocated for using approximation as a unifying thread of the first-year calculus curriculum (Roberts 1998; Zorn 1991). A unifying thread is a concept or theme woven throughout the subject matter which has the potential to bind it together into a cohesive, unified whole (Hilbert et al. 2010). Zorn (1991) reported on a working group of 40 scientists and mathematicians convened in San Antonio, Texas to discuss the core content of the first-year calculus curriculum:

The theme of approximation, it was agreed, is central to the calculus - what it is and what it does. Two main interpretations of the idea of approximation emerged: approximation in the sense of numerical analysis (i.e., producing estimates, with computable error bounds, to a priori existing quantities); and approximation as a conceptual idea (i.e., in the sense that the main objects of the calculus are defined by limits of approximations). The Riemann sum, for instance, can be viewed as either a technique for estimating an integral, or as part of the definition of integral itself (p. 4).

Zorn further articulated the working groups' agreement that, at a minimum, an informal treatment of the basic epsilon-delta idea (i.e., controlling outputs by controlling inputs) as it occurs in various contexts, such as approximation and error analyses, should be included given its importance to understanding and using the calculus. Reporting on the activity of the same working group in San Antonio, Keynes (1991) added that it is important for first-year calculus students to understand the concept of degrees of accuracy and think about how good a model can be when modeling physical and statistical data. Keynes also mentioned the group's perception of the importance of asymptotic approximation to a sound understanding of the behavior of functions.

Roberts (1998) reported on a reform project involving a working group of faculty from 26 liberal arts colleges seeking to develop a curricular core for a 1-year single variable calculus course. While the fundamental theorem readily surfaced as a connecting construct of the first-semester calculus, the working group found it more challenging to identify a unifying thread for the second-semester calculus. Ultimately, they agreed to “... build the course around 'precision and approximation', to investigate methodologies that produce exact solutions and when [those] approaches fail, to find ways to obtain approximate solutions with upper bounds on errors" (Roberts 1998, p. 
38). The working group believed, particularly in the case of the second-semester calculus, that approximation is a theme that provides cohesion to the collection of calculus ideas and techniques commonly found in Calculus II courses while at the same time, "...emphasizing the importance of making approximations" (Roberts 1998, p. 38).

More recently, calculus textbooks using approximation as a unifying thread to frame the first-year curriculum have surfaced (Hilbert et al. 2010; Shahriari 2006). Hilbert et al., authors of Calculus: An Active Approach, identify five unifying threads that generally run through first-year calculus curricula, one of which they entitle Approximation and Estimation. Shahriari (2006), author of Approximately Calculus, writes: "The theme of the book is approximations. Calculus is such a powerful intellectual tool since it enables us to approximate complicated functions with simpler ones. In fact, replacing a function locally with a linear-or higher order-approximation is at the heart of calculus" (p. xiii).

How, and to which level, should a calculus instructor introduce to students the idea of getting close enough - the idea of a lower or upper bound or approximation - in a first-year calculus course? Jungić and Mulholland (2014) explore that question and suggest that the comparison properties of the integral bring forward opportunities for students to (a) appreciate approximation as "one of the driving forces in calculus" (p. 1077); (b) understand that they have the tools to do tight approximations; and (c) appreciate the difference between knowing that a mathematical object exists and being able to calculate it exactly (Jungić and Mulholland 2014). The question posed by Jungić and Mulholland evidences a level of interest within the mathematical community around making approximation concepts more central in first-year calculus courses.

The present study is an outgrowth of its authors' prior research, What Does it Mean for a Student to Understand the First-Year Calculus? Perspectives of 24 Experts, which underscored a need for deeper examination of the first-year calculus curriculum (Sofronas et al. 2011). In that emergent study, the participating experts - 16 of whom are authors of widely used calculus textbooks - were interviewed for the purpose of better understanding expert perceptions regarding the calculus concepts and skills most fundamental to a solid student understanding of the first-year calculus (Sofronas et al. 2011). The participating experts raised five key concepts as important to student understanding of the first-year calculus: derivative, integral, limit, sequences \& series, and approximation. In light of earlier efforts within the mathematics community to frame the first-year calculus curriculum around approximation, which is connected to a number of the foundational calculus concepts including function, continuity, limits, derivatives, definite integrals, sequences and series (Asiala et al. 1997; Czocher et al. 2013a, b; Gordon 2011, 2012; Jungić and Mulholland 2014; Martin 2013; Oehrtman 2008, 2009; Oehrtman et al. 2014; Sealey 2014; Sealey and Oehrtman 2005; Yang and Gordon 2008; Zandieh 2000), the present study examines a more representative sample of calculus instructors teaching first-year calculus courses at higher education institutions in the U.S. to gain a baseline understanding of their perceptions about the role of approximation in the teaching and learning of calculus.

Literature on the use of unifying threads in the teaching and learning of calculus, and mathematics in general, is limited at best (Dorier 1995; Dray and Manogue 2010; Hathaway 2008; Shoenthal 2014). No study has looked at whether using approximation as a unifying thread of the first-year calculus is taking root in the instructional practices 
of calculus instructors in higher education. The purpose of this study is therefore to examine the following research questions:

1. Do calculus instructors perceive approximation to be important to student understanding of the first-year calculus?

2. Do calculus instructors report emphasizing approximation as a central concept andor unifying thread in the first-year calculus?

3. Which approximation ideas do calculus instructors believe are "worthwhile" to address in first-year calculus courses?

4. Are there any differences between demographic groups with respect to the approximation ideas they teach in first-year calculus courses?

\section{Background Literature}

This section outlines relevant literature about the use of unifying threads in the teaching and learning of mathematics, a dynamic view of approximation, and a relatively new body of research suggesting approximation concepts have the potential to help calculus students make sense of key concepts in the first-year calculus curriculum.

\section{Unifying Threads}

According to Riggle (1968), the use of curricular unifiers in the teaching and learning of mathematics supports mathematics as a study of structures as opposed to a study of unrelated ideas. For example, Shoenthal (2014) has identified Fourier Series as a unifying thread of the Calculus II curriculum “...to broaden [students'] appreciation for how interwoven mathematics is in the world around them" (p. 299) and to lay the groundwork for future applications of the topic. Framing curricula around unifying threads might address the problem of fragmented learning, which has historically plagued the teaching and learning of mathematics in higher education (Baroody et al. 2007; Berry and Nyman 2003; Galbraith and Haines 2000; Ferrini-Mundy and Graham 1994; Hiebert and Lefevre 1987; Kannemeyer 2005; Mahir 2009; Martin 2013; Porter and Masingila 2000; Schoenfeld 1988; Shoenthal 2014; Sierpinska 1987, 1990; Swinyard 2011).

Tall (as cited in Gravemeijer and Doorman 1999) addresses the issue of fragmentation in the calculus curriculum:

Mathematicians tend to make a typical error when they design an instructional sequence for calculus. The general approach of a mathematician is to try to simplify a complex mathematical topic, by breaking it up in smaller parts, [which] can be ordered in a sequence that is logical from a mathematical point of view. 'From the expert's viewpoint the components may be seen as a part of a whole. But the student may see the pieces as they are presented, in isolation, like separate pieces in a jigsaw puzzle for which no total picture is available' ... It may be even worse if the student does not realize that there is a big picture. The student may imagine every piece as an isolated picture, which will severely 
hinder a synthesis. The result may be that the student constructs an image of each individual piece, without ever succeeding in bringing all pieces together in one whole (pp. 112-113).

To gain a "big picture" understanding of the first-year calculus, students must build a coherent conception of its underlying mathematical structures. Curricular unifiers can make new math ideas more comprehensible through the construction of connections and relationships to previously studied topics, which support the development of a big picture understanding. Strang (1987) notes that calculus instructors are often "...very much inside the subject, teaching it but not seeing it" (p. 54). If students are to learn how to "speak" the language of calculus, instruction must move beyond simply teaching the "grammar" or rules of the calculus (Strang 1987).

Along a similar vein, Dorier (1995) offers three examples for what he calls unifying and generalizing concepts in mathematics: the axiomatization of linear algebra, the theory of groups, and the concept of limit. He argues that the success of a unifying and generalizing concept in mathematics stems not from its potential to find solutions to unsolved problems but rather from its power to generalize, unify, and therefore simplify the search for problem solving methods in mathematics. Dorier (1995) defines unifying and generalizing concepts as those that "... unify and generalize different methods, tools and objects, which existed previously in a variety of settings" (p. 177). According to Dorier (1995), a unifying concept is constructed in two stages: recognizing similarities between objects, tools and methods; and restructuring prior knowledge once the unifying concept becomes explicit to the learner as an object. This construction engenders a new and more sophisticated level of abstraction.

\section{A Dynamic View of Approximation}

The present study is framed around a dynamic view of approximation. According to Ramsey (1992), a dynamic view of approximation emphasizes the process of making an approximation, which is essentially a limiting process. "Used as a verb, 'approximate' means 'to carry or advance near; to cause to approach (to something) ... An approximation is an act or process and not just a relation. An approximation, thus becomes 'any methodological strategy which is used to generate or interpolate a result due to under-resolved data of deficits of analytic or calculational power" (p. 157).

According to Ramsey, it is commonplace for scientists to hold a static view of approximation, which presents approximation as a comparison relation between two structures. In this view, the validity of an approximation is evaluated solely by the magnitude of the error, or by placing a "...limit on the permissible discrepancy between theoretical and experimental values" (Ramsey 1992, p. 154). A dynamic view of approximation considers an expanded set of criteria used to judge the validity of an approximation rather than a simple consideration of the size of the error introduced by an approximation. Three additional criteria for evaluating the validity of an approximation, each internal to the theoretical structure of the approximation, are inherent to a dynamic view: (a) showing that better approximations lead to better predictions or smaller errors (i.e., controllability); (b) proving that the size of the error and the controllability are not the result of chance; and (c) demonstrating good theoretical motivation for the approximation strategy. It is essential, argues Ramsey (1992), to 
know something about the reliability of the theory and its calculational structure before conclusions can be made about the worth of a theoretical result which matches the experimental result exactly or within a specified range of error (Ramsey 1992, 158).

Although approximation strategies commonly presented within in a first-year calculus curriculum have already been validated by the mathematical community using the criteria outlined in Ramsey's description of a dynamic view of approximation, problems presented to first-year calculus students may vary in their potential to facilitate the student's view of approximation as a limiting process. For example, approximate $e^{0.2}$ and $e^{3}$ correct to 6 decimal places with Taylor polynomials may help students view approximation as an act or dynamic process as opposed to a product or comparison relation because it has the potential to allow students to experience the limiting process as they examine the numerical convergence (and the graphs) of the Taylor polynomials $T_{n}(x)$ to the functionf $(x)=e_{x}$. When $x=0.2$ the convergence is very rapid, but when $\mathrm{x}=3$ the convergence is much slower. By contrast, approximate the function $f(x)=\sqrt{x}$ by a Taylor polynomial of degree 2 at $\alpha=4$ and then calculate the accuracy of the approximation when $3 \leq x \leq 5$ is a reasonable exercise, but it focuses on a single error calculation and lacks the same potential for students to experience the limiting process.

\section{Leveraging Approximation to Understand Fundamental Concepts in Calculus}

A growing body of research suggests approximation ideas can be leveraged to support students' cognitive development of a logical and well-organized collection of connected schemas aligned with key calculus concepts. According to Oehrtman (2004, 2008, 2009), approximation ideas can be used to help students construct the conceptions needed for formal understanding of limit and limit-related concepts. Oehrtman (2009) investigated 120 calculus students' spontaneous reasoning about limit concepts and identified five strong metaphors for limits that served to influence their thinking. The most common was grounded in students' intuitions about approximation and error analyses. According to Oehrtman (2008, 2009), approximation metaphors for the limit are not only accessible but powerful given their close resemblance to the correct mathematical structure underlying the limit. Approximation metaphors lay the foundation for the eventual development of more formal conceptions of limit and also understanding of the underlying structures of other limit-related concepts of the firstyear calculus (Oehrtman 2008, 2009).

In addition, purposefully chosen approximation problems can help students develop a y-first perspective, which is important in understanding the formal definition of the limit (Oehrtman 2008). Swinyard (2011) claims calculus students naturally reason about limits from an x-first perspective and, as a result, they are challenged by the formal definition of the limit, which is structured around a y-first perspective. In other words, students find the dependence of delta upon epsilon counterintuitive and struggle with the idea of moving from a condition in the range to a condition in the domain (Oehrtman 2008; Oehrtman et al. 2008; Swinyard 2011). Crafting problems specifically designed to focus students' attention on the genuine need to reason from a range-first perspective (e.g., finding an approximation with sufficient accuracy for an identified purpose) may help students who otherwise might be unable to attend to the appropriate dependence (Oehrtman 2008). 
Oehrtman (2008) initiated the development of conceptually accessible instructional tasks across multiple contexts (e.g., gravitational force, falling objects, electrical charge) and across a number of key concepts of the first-year calculus (e.g., derivatives, definite integrals, and Taylor series) designed to reinforce approximation structures within those limit-based concepts. Using a gradual release model, those instructional tasks repeatedly prompt students to reflect on the approximation structure underlying the limit by considering the following questions, each from contextual, graphical, numerical and algebraic perspectives: 1) What are you approximating? 2) What are the approximations? 3) What are the errors? 4) What are the bounds on the size of errors? 5) How can the error be made smaller than any predetermined bound? (Oehrtman 2008, p. 78). That work has led to the development of Project CLEAR Calculus, a research-based "...effort to make calculus conceptually accessible to more students while simultaneously increasing the coherence, rigor, and applicability of the content learned in the courses" (Oerhtman and Martin 2015, para. 1). This project, aimed at addressing problems associated with fragmentation in the calculus curriculum, provides a strong conceptual foundation for calculus through an approximation framework $^{2}$ used to develop 36 labs spanning differential, integral and multivariable calculus. Examination of the impact of those labs on students' understanding of the central concepts in calculus has yielded positive results (Oerhtman and Martin 2015).

Approximation ideas can also be leveraged to support students' understanding of the structure of the Riemann integral. Sealey (2014) developed the Riemann Integral Framework to examine how students construct an understanding of the structure of the Riemann integral. The five layers of the Riemann Integral Framework - the Orienting Layer, Product Layer, Summation Layer, Limit Layer and Function Layer-decompose the Riemann integral "in the form of $\lim _{n \rightarrow \infty} \sum_{i=1}^{n} f\left(x_{i}\right) \Delta x$, where xi represents any $\mathrm{x}$-value on the ith subinterval, $\Delta x=\frac{(b-a)}{n} n$, a is the left endpoint of the interval, and $b$ is the right endpoint of the interval" (p. 231). Approximation ideas connect to several layers of the Riemann Integral Framework as in the case of the Limit Layer:

Increasing the number of rectangles under a curve is an example of thinking about the limit in terms of better approximations, even if one does not calculate

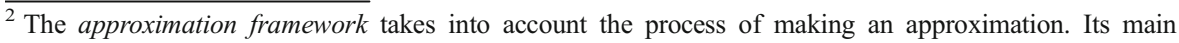
components include: (a) approximations believed to be close in value to an unknown actual quantity, (b) associated errors, and (c) error bounds: For each approximation, there is an associated error, Error $=\mid$ unknown quantity-approximation. Consequently, a bound on the error allows one to use an approximation to restrict the range of possibilities for the actual value as in the inequality:
}

approximation-bound $<$ unknown quantity $<$ approximation + bound

An approximation is contextually judged to be accurate if the error is small, and a good approximation method allows one to improve the accuracy of the approximation so that the error is as small as desired. An approximation method is precise if there is not a significant difference among the approximations after a certain point of improving accuracy (Oehrtman et al. 2014, p. 73). 
the exact value of the limit. When students discuss how to find an approximation accurate to within any pre-determined bound, they are working within the Limit Layer by attending to the process of obtaining approximations that are progressively closer to the value of the definite integral (Sealey 2014, pp. 240-241).

Findings indicate that students struggle most with the Product Layer of the Riemann Integral Framework. "...the Product Layer, is composed of the multiplication of two quantities, $f\left(x_{i}\right)$ and $\Delta x$, where $f\left(x_{i}\right)$ may be conceptualized as a rate and $\Delta x$ as a difference" (Sealey 2014, p. 231). According to Sealey (2014), a fundamental idea in understanding the Product Layer, is recognizing that the product formulas apply only when the factors are constant (e.g., in the case of a constant velocity over a time interval) and the need to approximate arises in contexts where those terms are not constant.

According to Martin (2013), Taylor series are often students' first exposure to function approximation techniques. Students often find it challenging to make sense of Taylor series because it has a complex structure that requires an understanding of many key calculus concepts only some of which include error and error bounds, interval and radius of convergence, and center (Martin 2013). A Taylor series is a special case of a power series and is “... a strategy for obtaining better and better approximations to a function at a point by constructing a polynomial whose coefficients are successive derivatives of the function at that point. The Taylor expansion can be thought of as a procedure that takes two arguments, the first being the function that is being approximated and the second is the location of the point about which the Taylor expansion is taking place" (Yerushalmy and Schwartz 1999, p. 907). According to Yerushalmy and Schwartz (1999) there is value in encouraging students to "...inspect and analyze the degree to which a given order Taylor expansion is appropriate for a function" (p. 909). Preparing learning activities that cause students to reflect upon the "locality" of the Taylor series expansion can motivate the introduction to other techniques for approximating functions (e.g., Fourier, wavelet) and “...can turn approximation into an activity of analyzing, comparing, and even inventing new methods of approximation" (p. 909).

\section{Methodology}

The following sections outline the development of the survey instrument administered to study participants and the procedures for sampling, data collection and data analysis.

\section{Survey Instrument}

A survey instrument was developed to examine approximation-related perceptions and self-reported instructional practices of calculus instructors who have taught first-year calculus courses in higher education. A review of the literature was conducted to establish item stems for the survey. Content validity was established through consultations with six experts in the field. Items stems were added, omitted and refined based upon the feedback of those experts. The survey (see Appendix) includes a series of demographic questions, 20 Likert-scale item stems, an open text box following each 
Likert-scale item stem to allow participants the option of explaining their rating on the item stem, and two open-response questions.

\section{Procedures for Sampling, Data Collection and Data Analysis}

A stratified random sampling method was used to identify the sample for this study. The National Center for Educational Statistics database (http://nces.ed.gov/ collegenavigator/) was used to identify all 2-year and 4-year higher education institutions in each state within the United States as well as Washington D.C., Puerto Rico, and the Virgin Islands. A total of 259 institutions were randomly selected through the sampling design. Of those, 77 institutions were excluded from the sample for the following reasons: (a) the institution did not offer calculus courses; (b) the institution had no mathematics department most typically because it was a special-focus institution; or (c) the institution's website did not include publically available mathematics faculty contact information. Despite eliminating 77 institutions for those reasons, the remaining institutions represented nearly all of the U.S. states, Washington D.C., Puerto Rico and the Virgin Islands. A database of 3930 mathematicians was compiled using the name and email address for each mathematician listed on the websites of the selected institutions. All were recruited to participate in the online survey developed for the purpose of this study. Of the 3930 mathematicians recruited, only those who had taught first-year calculus courses were eligible to participate in the study, opening the possibility for a large percentage of ineligible candidates and lower response rate.

Qualtrics, a secure internet-based survey technology provider, was used as the platform to create and distribute the survey. Data were collected over a period of 6 months. Quantitative data were exported to Software Package for the Social Sciences (SPSS) and analyzed using descriptive statistics, t-tests and analysis of variance procedures for statistically comparing the means of the demographic groups of interest. Qualitative data were coded using a posteriori categorical content analysis techniques. Members of the research team and trained research assistants isolated dominating themes and defined ranges of themes, indicators for the occurrence of a theme and rules for coding (Kortendick and Fischer 1996). A total of $N=279$ calculus instructors, $31 \%$ female and $69 \%$ male, participated in the study. The demographics of the final sample for this study are reported in Table 1.

\section{Results and Discussion}

Discussion of the research findings is organized around four research questions:

1. Do calculus instructors perceive approximation to be important to student understanding of the first-year calculus?

2. Do calculus instructors report emphasizing approximation as a central concept andor unifying thread in the first-year calculus?

3. Which approximation ideas do calculus instructors believe are "worthwhile" to address in first-year calculus courses?

4. Are there any differences between demographic groups with respect to the approximation ideas they teach in first-year calculus courses? 
Table 1 Summarizes the demographic composition of the study participants

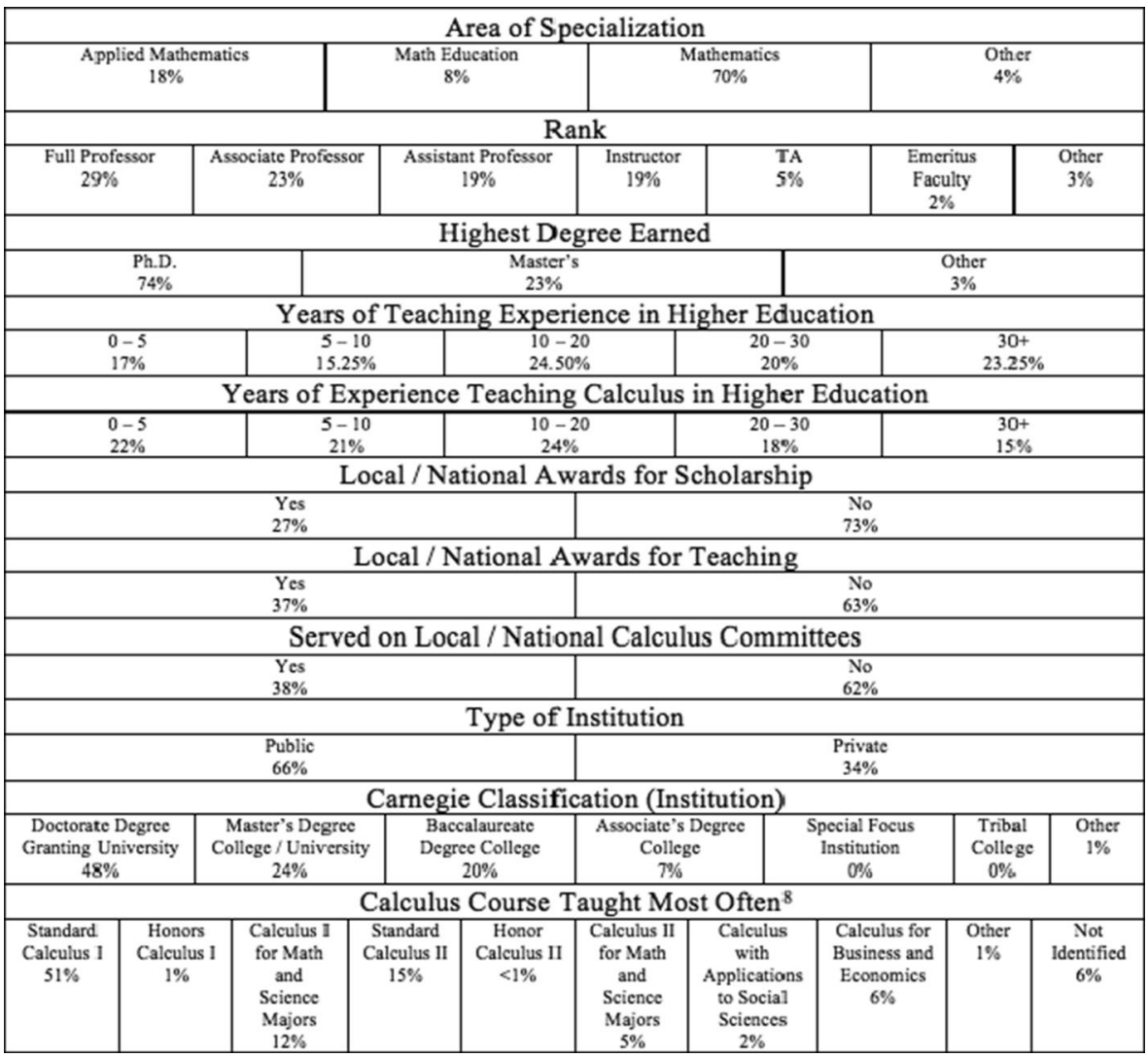

\section{Research Question 1: Do Calculus Instructors Perceive Approximation to Be Important to Student Understanding of the First-Year Calculus?}

To answer research question 1, the researchers extracted themes and patterns from participants' written responses to open-ended question 21 on the survey instrument (see Appendix). In this study, $89 \%$ of the responding participants agree that approximation ideas are important to student understanding of the first-year calculus. Participant $\mathrm{R}$ 7 $71 \mathrm{U}^{3}$ wrote, "Approximation is the heart of the limit and the limit is the heart of calculus”. Participant R_cvi shared a similar view:

There is essentially no topic in the application of calculus ... in which approximation does not play a central role. The theory of calculus ... is really a theory of

\footnotetext{
${ }^{3}$ In this study, personal identifiers were not collected from survey participants. Qualtrics randomly assigned each participant a 17-character "ID" linked to their responses for purposes of data organization and analysis. The first few characters from those Qualtrics-assigned IDs are used in this paper when sharing participants' written comments.
} 
approximation. The best way to understand the idea of a limit is in terms of approximation and acceptable error.

Several themes emerged from the data shedding light on reasons participants perceive approximation to be important to student understanding of the first-year calculus, including: (a) approximation is a primary building block of the calculus, (b) approximation is foundational to understanding the fundamental concepts in calculus, (c) approximation can motivate the study of calculus topics and-or make calculus topics more meaningful to students, (d) approximation has relevance to real world or applied problems, which are rarely exact, (e) approximation is a critical component of the knowledge base of science, technology, engineering, and mathematics [STEM] majors, and (f) approximation ideas have historical significance to the development of the calculus. Participant R_1S7 wrote, "[Approximation] is the foundation of the limit concept which, in turn, is the unifying concept of differential and integral calculus and of infinite series. Why bother to discuss infinite series at all if not for the purpose of obtaining algebraic or trigonometric approximations to transcendental functions?"

Many participants attributed their ability to make approximation concepts central in their own teaching of first-year calculus courses to widely available graphing technologies. Participant R_4O7's response typified this point:

I use technology very extensively in my first-year calculus classes. It is a very efficient method to illustrate approximation whether you are talking about partial sums of infinite series or secant approximations to the tangent line. It is also interesting to show how the calculator gets 'tripped up' by the approximation algorithms that it uses. For example, ask the TI 84 to find the value of dy/dx of $y$ $=\operatorname{abs}(x)$ at $x=0$ and you will get a value of 0 ! The reason for that is the calculator uses secant approximations on either side of the vertex, which will always give a horizontal line!!!

\section{Research Question 2: Do Calculus Instructors Report Emphasizing Approximation as a Central Concept and-or Unifying Thread in the First-Year Calculus?}

To answer research question 2, the researchers examined data associated with Item Stems 1 and 2 on the survey instrument (see Appendix). Analyses of the data reveal that $51 \%$ of the responding study participants "Agree" or "Strongly Agree" that they present approximation as a central concept in their own teaching of the first-year calculus (see Fig. 1). Fewer (40\%) "Agree" or "Strongly Agree" that they use approximation as a unifier of the first-year calculus curriculum in their own teaching (see Fig. 2). Five themes emerged that explain calculus instructors' emphasis on approximation as a central concept and-or unifying thread in their teaching: (a) approximation can illuminate reasons for learning calculus and-or help students see the "big picture"; (b) most interesting functions are not elementary functions and approximations are useful in dealing with those situations; (c) approximation ideas facilitate understanding of fundamental concepts in the first-year calculus (e.g., limit, derivative, and integral) and, therefore, reduce the likelihood that calculus will 


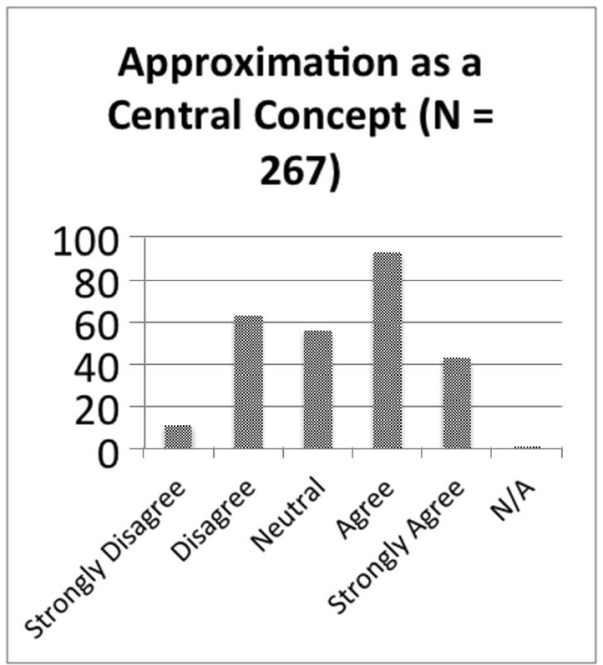

Fig. 1 Participants' agreement that approximation is emphasized as a central concept in their own first-year calculus course(s)

degenerate into a study of rote and meaningless computation; (d) linear approximation is the foundation of differential calculus; and (e) participants with a background in applied mathematics or numerical analysis acknowledged their specialization as a factor in the emphasis they place on approximation in their calculus courses.

A number of themes emerged among those participants who do not emphasize approximation as a central concept and-or unifying thread in their first-year calculus courses. First, the most common theme was that approximation is not germane to enough topics in the first-year calculus to warrant excessive emphasis. Stated Participant R_0pl, "I use approximation to motivate the precise definitions of the derivative of a function at a point or the value of a definite integral, but I would not claim that approximation is the central concept that I wish to convey." Likewise, some

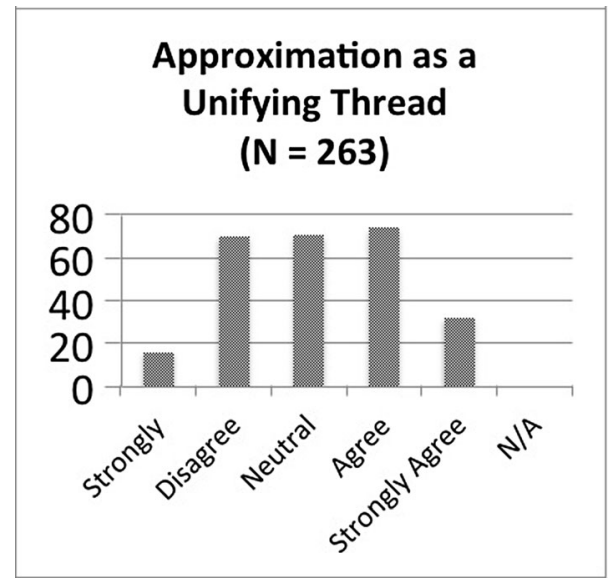

Fig. 2 Participants' agreement that approximation is used as a unifying thread in their own first-year calculus course(s) 
participants viewed approximation as an application of calculus and could not justify more than a peripheral emphasis on it in their teaching of first-year calculus.

Second, constraints such as overcrowded calculus syllabi, limited technology access or math department-imposed technology bans, little freedom to make curricular decisions, and ill-prepared students fail to afford some calculus instructors options for presenting approximation as central or unifying in their first-year calculus courses. The response of Participant R_cFM typified that concern: "Yes, [approximation] is very important; however, due to time constraints and student preparation, namely, I get bogged down on explaining a lot of the material because my students are not generally strong. I am not able to do justice to the role of approximation to the extent that I'd like." Those participants were optimistic that students studying STEM disciplines would have adequate exposure to approximation ideas in subsequent numerical analysis coursework.

Third, some participants reported presenting other concepts (e.g., limit, study of change) as central and-or unifying in their first-year calculus courses. According to Participant R_0Bc, "Generally, I follow whatever is the suggested text. Approximation is right there in the notion of a limiting process, which of course, is central to the definitions of derivatives and integrals. But probably I would say the notion of limit, the thing that ultimately 'beats all approximations' is really the central concept."

Finally, some participants expressed concerns surrounding the use of technology in the teaching and learning of calculus. According to Participant R_9GH, approximation:

...is an important application. However, after many years of trying many different approaches, including using technology, I have found too much technology detracts from a calculus course and many students end up with a misunderstanding of the importance of mathematics and, in particular, calculus.

Similarly, Participant R_d5n observed, “Approximation arises in limits, differentiation, integrals, differentials, and error estimates, but I try to be careful because too many students will then use a calculator to find answers rather than their own brain."

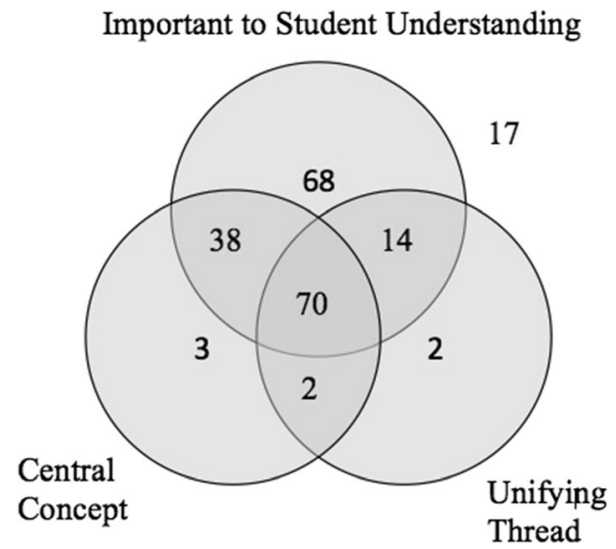

Fig. 3 Graph depicting participants' perceptions of approximation $(N=214)$ 
The diagram in Fig. 3 summarizes the perceptions of responding participants regarding the role of approximation in their own first-year calculus courses. For instance, 70 participants responded that they do perceive approximation to be important to student understanding of the first-year calculus, do emphasize approximation as a central concept, do use approximation as a curricular unifier in their own teaching; 68 participants responded that they do perceive approximation to be important to student understanding of the first-year calculus, do not emphasize approximation as a central concept, do not emphasize approximation as a unifying thread in their own teaching; 38 participants responded that they do perceive approximation to be important to student understanding of the first-year calculus, do emphasize approximation as a central concept, do not use approximation as a curricular unifier in their own teaching.

\section{Research Question 3: Which Approximation Ideas Do Calculus Instructors Believe are "Worthwhile" to Address in First-Year Calculus Courses?}

To answer research question 3, the researchers examined data associated with Items Stems 3-20 on the survey instrument (see Appendix). The findings in this section are organized around the topics of error analyses, derivative concepts, functions, series and definite integrals.

\section{Error Analyses}

Findings related to error analyses focused on tolerance, estimating error, acceptable levels of error, and discriminating between approximation techniques. "If the errors are not tolerable, approximations are useless" stated Participant R_e4w. Fifty percent of the responding participants reported stressing the importance of knowing how good an approximation is in their first-year calculus courses, though more so in second-semester calculus than first-semester courses. Participant R_89a captures participants' views surrounding the significance of context in determining how good an approximation is:

We often, several times in the semester, discuss whether an error of, say, 0.001 is 'good.' Some students are aware and the others become aware that the scale and setting make all the difference. Relative error is the indicator we want. A measure of $0.001 \mathrm{~m}$ is useless compared to the size of a hydrogen atom.

Fifty seven percent of responding participants "Agree" or "Strongly Agree" that they discuss methods for calculating or estimating the error in an approximation, particularly when discussing Taylor series, differentials, linearization, approximate values of linear functions, and numerical methods for estimating definite integrals. Numerical integration and Taylor series were identified as topics in which students can readily discriminate between various approximation techniques, though only $34 \%$ of participants reported including those kinds of investigations in their first-year calculus courses. As previously noted, the focus for some was simply on discussion around the importance of knowing how good an approximation is and not on actual error calculations. 
Forty-four percent of responding study participants "Agree" or "Strongly Agree" that they discuss the notion of acceptable levels of error in an approximation. Participant R_6Rw responded:

I usually point out that this is an important issue, but it is secondary to understanding what they are approximating and getting an approximation to start with. If students don't know what a derivative is, there's not much point in worrying about how good a specific estimate of it is. Sometimes though, the issue of accuracy of an estimate can help inform their understanding of a procedure, such as the rectangle rule for estimating a definite integral.

Participants reported several reasons for not devoting attention to error analyses in their first-year calculus courses. Lack of time again surfaced as a major constraint, as did instructor perceptions of weak mathematical backgrounds among first-year calculus students. Participants reported that first-year calculus students often struggle to grasp the concept of tolerance, quantify the error in an approximation, or appreciate the subtle notion of acceptable levels of error. If discussed at all, acceptable levels of error might be demonstrated in an example or two (e.g., positioning a robot arm within some specified tolerance of a target location by determining how accurately the hydraulic pressure that activates the arm must be controlled). Other reasons for deemphasizing error analyses in first-year calculus courses included lack of alignment with (nonhonors) course learning goals, difficulty assessing student understanding, and student disinterest in error analyses concepts. Participant R_cBd responded, "The kids in my class are typically not interested in such fine points. Thus, when I try to explain such things, they usually become distracted knowing I cannot test on such material. I would like to do more, but it doesn’t really fit into a freshman calculus course."

\section{Derivative Concepts}

The findings related to derivative concepts focused on approximating the slope of the tangent line and bounding the error in an approximation of the slope of the tangent line. Not surprisingly, $95 \%$ of responding participants "Agree" or "Strongly Agree" that they show students how to approximate the slope of the tangent line using secants. Participants suggested that this approximation is an accessible concept for students that is easily demonstrated using technology and represents one way to introduce the idea of the derivative. Given the results related to error analyses reported in Section "Error Analyses", it is also not surprising that significantly fewer responding participants (69 \%) reported explaining to their first-year calculus students that the error in approximating the slope of a tangent line can be made smaller than any predetermined bound. A number of participants reported that, if they do discuss the error in the slope of the tangent line, it is non-rigorous and connected to limit concepts. Participant R_9mH responded, "I present this idea to my students, but I do not ask them to demonstrate this fact themselves. What I emphasize is that in the limit, this approximation becomes exact." Participant R_9mH responded that the question of precision is properly handled by discussion of the second derivative: “...This I consider to be part of the more general Taylor polynomial discussion that is had in Calculus II, where the 'next' derivative is proven to relate to the Taylor error." 


\section{Functions}

The findings related to function concepts focused on linearization and approximation of functions. There was strong agreement among responding participants $(83 \%)$ that they discuss linearization techniques in their first-year calculus courses. Linearization was described as "the essence of calculus" by Participant R_cBd and as "... a fundamental theme of the chapters on differentiation" by Participant R_81v. Clearly perceived as a central idea of the calculus, linear approximation was even described by some participants as a possible "bridge concept," in the first year calculus. For instance, Participant R_cTs wrote, "This helps set the stage for Taylor polynomials in the next course which, from my experience teaching it, is often a hard idea for students to grasp without connecting it first to the linearization done in first-semester calculus." Likewise, Participant R_0Bc responded, "Yes, linear approximation is central, and it is the part that generalizes beautifully in multivariable calculus, linear algebra, differential geometry, and beyond." While only $44 \%$ of responding participants "Agree" or "Strongly Agree" that function approximation is emphasized as a main theme in their first-year calculus courses, analysis of written comments from the complementary $56 \%$ of participants indicated that they generally $d o$ address approximation of functions in their first-year calculus courses and view it as important, but would simply not classify it as a "main theme."

\section{Series}

Study findings related to series focused on motivating the study of power series, approximating the values of complicated functions using power series, bounding error, estimating the error term in a Taylor polynomial, number of terms in a Taylor polynomial, and approximating a finite or infinite sum using power series.

Seventy-two percent of responding participants reported that they discuss reasons for studying power series in their first-year (but mostly second-semester) calculus courses. According to Participant R_6Rw, "To the extent that one now covers power series, or anything for that matter, one has to motivate them. Since power series seem hard for students, [they] need more motivation for working on them than for some other topics." Seventy percent of participants "Agree" or "Strongly Agree" that they demonstrate how power series can be used to approximate the values of complicated functions and believe students to like those demonstrations. Participant R_cTs reported:

This is my students' favorite class as I'm able to show via Mathematica examples of how well the polynomials approximate functions. There is also a small demo they can view at home - a game where they try to avoid a projectile that is aimed using increasing orders of polynomials, with readouts showing their position, speed, and acceleration that are used to select the angle of fire.

Seventy-two percent of responding participants "Agree" or "Strongly Agree" that (under suitable assumptions) they emphasize that the partial sum of a power series represents an approximation of a function at a point and, within the interval of 
convergence, this approximation can be made as accurate as possible by increasing the number of terms in the partial sum.

Fifty-eight percent of responding participants "Agree" or "Strongly Agree" that they demonstrate how to estimate the error term in order to evaluate how good a Taylor Polynomial approximation is, while $53 \%$ demonstrate how to use the error term for a Taylor Polynomial to determine how many terms of a power series are sufficient to guarantee that an approximation has a given accuracy. Participant R_89a comments, "In my opinion, there's not much point unless you can bound the error. I also teach this in Calculus I, where I explain that it is plausible that the second derivative controls the error of a linear approximation; then we use (without formal proof) that bound." Written comments suggested time constraints and weak student backgrounds impede some calculus instructors from devoting attention to demonstrations of using the error term to evaluation how good a Taylor Polynomial approximation is or to determine the number of terms needed to guarantee a Taylor polynomial approximation has a given accuracy.

While some participants indicated that using definite integrals to approximate a finite or infinite sum is a year 2 calculus topic at their institutions, $69 \%$ of responding participants "Agree" or "Strongly Agree" that they show how to approximate a finite or infinite sum using definite integrals in their first-year calculus course.

\section{Definite Integral}

Study findings related to definite integrals focused on techniques for approximating definite integrals, Riemann sums, error in approximating definite integrals, and examples of definite integrals best approximated numerically.

Eighty-five percent of the responding participants in this study discuss techniques for approximating definite integrals in their first-year calculus courses and $72 \%$ share examples of definite integrals that are best approximated numerically. Participant $\mathrm{R}$ _8Ar reported, "I think this is essential if students are to understand the integral as something more than the result of antidifferentiation." Specific approximation techniques identified included rectangular Riemann approximations (left, right, midpoint), trapezoidal Riemann approximations, and Simpson's Rule; although, calculus programs have omitted the latter two techniques according to some participants. There was also strong agreement (93\%) among participants for using Riemann sums to discuss estimating the value of a definite integral; however, they cautioned that students can find Riemann sums difficult, unimportant, or even - in the case of those who have already had exposure to calculus in high school-burdensome.

Consistent with findings in Section "Error Analyses", less than half of the responding participants in this study (45\%) demonstrate in their first-year calculus courses how to quantify the error associated with an approximation of a definite integral. Time constrains and weak student backgrounds were again cited as reasons for not attending to the error associated with a definite integral approximation.

\section{Research Question 4: Are There Any Differences Between Demographic Groups with Respect to the Approximation Ideas Taught in First-year Calculus Courses}

$T$-test and ANOVA procedures were used to identify significant differences between demographics groups on item stems 1-20. Analysis of survey data showed a number of 
significant differences between the group of participants who reported having served on calculus committees at the local and-or national level $(N=103)$ and the group of participants who reported never having done so $(N=170)$. Table 2 shows the item stems on the survey for which there were significant differences between the two groups:

All participants who had served on local and-or national calculus committees agreed more strongly with the item stems identified in Table 3 . They agreed more strongly that they (a) emphasize approximation as a central concept. (b) use approximation as a unifying thread, (c) discuss linearization, and (d) share examples of definite integrals that are best approximated numerically. They also agreed more strongly with item stems 8 and 19, which involve error analyses.

To better understand the two demographic groups, cross-tabulations were run between the demographic of having served / not served on a calculus committee and each of the other demographics in this study. The shaded areas of the Table 3 highlight the demographic differences between the two groups. A higher percentage of the calculus instructors who had served on local and-or national calculus committees-

Table 2 Item stem means for participants who served on local and-or national calculus committee $(N=103)$ and participants who had not served on local and-or national calculus committees $(N=170)$

Local and-or national calculus committees

Item stem

In my own teaching of the first-year calculus, ...

Served Not served $\mathrm{t}$

df

1. I emphasize approximation as a central concept in the calculus curriculum.

$3.64(1.18) \quad 3.19(1.08) \quad 3.148 * * 263$

2. I use approximation as a unifying thread to connect

$3.33(1.19) \quad 2.99(1.05) \quad 2.406 * \quad 259$ many of the key ideas in the curriculum.

3. I stress the importance of knowing how good an approximation is.

4. I discuss methods for calculating or estimating the error in an approximation.

5. I discuss the notion of acceptable levels of error $\quad 3.48$ (1.05) $2.94(1.10) \quad 3.931 * * * \quad 256$ in an approximation.

6. I provide opportunities for students to discriminate between various approximation techniques to identify

$3.21(1.18) \quad 2.89(1.13) \quad 2.180 * \quad 255$ which may work better in given situations.

8. I further explain that the error in that approximation (i.e., the difference between the slope of the tangent line

$3.68(1.03) \quad 3.21(1.01) \quad 3.603 * * * 257$

$3.60(1.01) \quad 3.25(1.01) \quad 2.665^{* *} \quad 253$

$4.06(1.03) \quad 3.72(1.11) \quad 2.480 *$ and the slope of the secant line) can be made smaller than any predetermined bound.

10. I discuss techniques for locally approximating differentiable $4.43(0.66) \quad 3.90(0.97) \quad 4.793 * * * \quad 252$ functions with linear functions (i.e., linearization).

19. I demonstrate how to quantify the error associated with an approximation of a definite integral.

20. I share examples of definite integrals that are best approximated numerically because the anti-derivative of a function is hard or impossible to determine.

$*=p<.05, * *=p<.01, * * *=p<.001$. Standard deviations appear in parentheses below the means 
Table 3 Demographic characteristics of participants who have or have not served on local and-or national calculus committees

\begin{tabular}{lll}
\hline Demographic & $\begin{array}{l}\text { Served on calculus } \\
\text { committees }\end{array}$ & $\begin{array}{l}\text { Did NOT serve on calculus } \\
\text { committees }\end{array}$ \\
\hline $\begin{array}{l}\text { Presented at calculus conferences or } \\
\text { workshops }\end{array}$ & $36 \%$ & $9 \%$ \\
$\begin{array}{l}\text { Teaching award recipient } \\
\text { Scholarship award recipient }\end{array}$ & $52 \%$ & $28 \%$ \\
Peer-reviewed pub(s) on calculus topic & $26 \%$ & $28 \%$ \\
Calculus textbook author & $17 \%$ & $10 \%$ \\
20+ peer-reviewed publications & $26 \%$ & $1 \%$ \\
20+ years teaching in higher education & $68 \%$ & $11 \%$ \\
20+ years teaching calculus in higher & $55 \%$ & $20 \%$ \\
$\quad$ education & $49 \%$ & $20 \%$ \\
Full professor & Male: $73 \%$ & $19 \%$ \\
Gender & Female: $27 \%$ & Male: $68 \%$ \\
& $77 \%$ & Female: $32 \%$ \\
Ph.D. & Mathematics: $69 \%$ & $73 \%$ \\
Area of specialization & Applied math: $18 \%$ & Mathematics: $70 \%$ \\
& $39 \%$ & Applied math: $18 \%$ \\
Served as mathematics department chair $\%$ & $63 \%$ \\
Public institution & $74 \%$ & $49 \%$ \\
Doctorate degree granting institution & $49 \%$ & \\
\hline
\end{tabular}

when compared with those who had not - reported (a) presenting at calculus conference and workshops; (b) receiving awards for their teaching; (c) publishing peerreviewed articles; (d) publishing on calculus topics and calculus textbooks; (e) teaching and teaching calculus in higher education for more than 20 years, (f) holding the rank of full professor, and (g) serving as a mathematics department chair.

\section{Conclusions and Implications}

This baseline study provides both quantitative and qualitative findings on whether the responding first-year calculus instructors view approximation to be a central concept and-or a unifying thread of first year calculus and if their perceptions about approximation ideas are reflected in their reported instructional practices. To this point, no study has directly investigated what first-year calculus instructors perceive to be the role of approximation in the teaching and learning of the first-year calculus. The large majority ( $89 \%)$ of study participants agreed that students' understanding of approximation is important to their understanding of the first-year calculus. Those participants further elaborated that approximation is a primary building block of the calculus and is foundational to the development of an understanding of many of the key concepts in the first-year calculus. This finding alone underscores the need to probe deeper to 
understand how calculus instructors frame their courses to include approximation concepts and, more specifically, which approximation ideas calculus instructors perceive to be worth addressing in their actual teaching of the first-year calculus. While $89 \%$ of participants reported that they do view approximation as important to student understanding of the first-year calculus, significantly fewer are translating that view into an instructional approach that presents approximation as a central concept $(51 \%)$ or unifying thread (40\%). Participants reported the following four primary reasons for such an incongruity:

First, some participants of the present study reported that they do not perceive approximation to be a curricular unifier of the first-year calculus inasmuch as it is not germane to a sufficient number of topics in the first-year calculus and is therefore better presented as an application of calculus. Ironically, when the calculus concepts or topics participants collectively identified as related to approximation ideas are compiled, the potential for approximation to be used as one possible unifying thread of the first-year calculus is even more clear: numerical limits, definition of limit, definition of the derivative, derivative values, tangent line approximation, differentials, error estimation, function change, function roots / Newton's method, linearization, integration, Riemann sums, Taylor polynomials / Taylor series, Newton's 2nd Law, Einstein's equation for F, L'Hopital's rule, Euler's Method, and approximations of irrational numbers.

Second, participants identified a number of impediments to emphasizing approximation as a central concept and-or unifying thread in their own teaching of first-year calculus courses: (a) many participants cited an already overcrowded calculus syllabus with no room or time to integrate approximation-related course learning goals; (b) others expressed that they had limited freedom to make curricular decisions in mathematics departments that often compelled the adoption of common first-year calculus syllabi and-or textbooks lacking an emphasis on approximation ideas or other more conceptually-oriented topics. For example, Participant R_9oY shared, "I agree [approximation] is important; however, the emphasis on closed form calculations which dominate homework (not under my control) and textbooks (same), make it hard to find time to discuss these topics"; (c) students' weak mathematical backgrounds were also cited by many participants as a reason for not emphasizing approximation concepts as central or unifying in the first-year calculus curriculum. Approximation ideas, they claimed, are too subtle for non-honors students to understand and do not stimulate interest, or worse, can cause disdain. According to Dorier (1995), some students do find it challenging to understand unifying concepts and often lack the necessary prerequisite knowledge. Moreover, not all students are prepared to invest the effort required to reflect on mathematical ideas and contexts on a meta-cognitive level. Such variables do limit the likelihood of students understanding a unifying and generalizing concept. Seeing familiar mathematical situations from a new and more unified perspective is a "quantum leap" that can be very difficult for students to make. Thompson (1985) reported resistance and frustration from answer-oriented students when trying to teach unifying and generalizing concepts: "If getting right answers was not the name of the game, then they did not know what the game was. They did not understand that 'the answer' was most typically a method or a generalization of a method, and not a number" (p. 231); and finally (d) some participants reported a lack of familiarity with approximation ideas. Gordon (2012) acknowledged many calculus instructors are not 
acquainted or comfortable with numerical methods and shy away from introducing them in their first-year calculus courses.

Third, some participants reported a preference to emphasize other concepts or themes to unify the first-year calculus curriculum (e.g., limit, change) or to simply focus on the techniques of calculus rather than approximation ideas. The calculus text by Hilbert et al. (2010) identifies five unifying themes of the first-year calculus, demonstrating that a number of contemporaneous threads can serve to unify the calculus curriculum. Some participants, like Participant R_0AR, acknowledged more than one viable curricular unifier for the first-year calculus:

The Calculus I-II sequence (one full year at my institution) moves from approximating a slope (the derivative) to approximating an area (the definite integral) to approximating a function (Taylor series). Although I prefer to think of differential equations as the organizing principle for our first-year calculus, it's just as logical to think of approximation as being at the heart of the big concepts of calculus.

Fourth, concerns were raised by some participants related to the role and availability of technology in the teaching and learning of first-year calculus as reasons for not emphasizing approximation as central or unifying in the first-year calculus, as expressed by Participant R_ePU, “[Technology] is helpful in computations. I try to avoid using technology as much as possible though. I want my students to be able to think, not use a calculator or computer program."

Conversely, participants who do perceive approximation to be a curricular unifier of the first-year calculus identified approximation as foundational and connected to the overarching purpose of the calculus, as Participant R_1B7 articulated, "The whole point of differential calculus is to approximate polynomials, usually linear ones." Those participants expressed that approximation ideas form part of the connective tissue of the calculus and to learn calculus without understanding approximation ideas is to learn calculus without meaning. Participant R_3HO commented, "I discuss approximations a bit more than some of my colleagues. Otherwise, the notion of limit makes little sense except as a flaming hoop for students to jump through." Study participants who serve on local and-or national calculus committees reported significantly stronger agreement with placing emphasis on approximation as a central concept and as a unifying thread in their own first-year calculus courses.

An unexpected finding of this study emerged from a percentage of participants who reported in their open responses that the act of taking the survey in this study prompted them to begin to rethink the way they frame their own first-year calculus courses. As one example, Participant R_0Ni offered: "I think I could do a better job of highlighting [approximation] as an overarching theme that is central to calculus and is a conceptual unifier of many calculus topics." Likewise, Participant R_4O7 responded:

I agree that approximation is an important concept AND after taking this survey I can see teaching calculus using approximation as the main theme. The rate of change theme offers many opportunities for real-life applications but I can see how 
using approximations from the beginning would offer other opportunities. It is an interesting idea and I would love to incorporate more of this theme into my lessons.

Ultimately, approximation will materialize as a unifying thread in the first-year calculus curriculum only to the extent that calculus instructors consciously and explicitly frame it as a unifying thread. Acknowledgements from participants that simply taking the survey in this study has caused them to think more deeply about approximation and how it can be brought into their first year calculus courses affirm the notion that instructors' perceptions have the potential to shape what is emphasized or included in the curriculum and what is incorporated into their teaching. Importantly, they are promising indicators of the potential for the findings of this study to invigorate discussion within the broader mathematics education community: Can approximation ideas be leveraged in ways that have the potential to help students build greater understanding of key ideas in the firstyear calculus? Are there ways to make approximation more central in our teaching? Could approximation serve as a unifying thread in first-year calculus course?

To teach approximation as a unifying thread or not, that really is the big question. There is no one-curriculum-fits-all in first year calculus today. Mathematics departments omit or emphasize topics differently to design a first-year calculus program that reflects the purpose of learning calculus, especially given present-day technological innovations. Notwithstanding, research referenced in this paper is suggesting that approximation ideas are foundational to the Calculus and form part of its connective tissue. Perhaps participants in this study expressed it best: To learn calculus without understanding approximation ideas is to learn calculus without meaning.

Acknowledgments The authors wish to thank the following experts who served as reviewers during the development of the survey instrument for their valuable contributions: Roland Minton, Robert Smith, Sheldon Gordon, James Hurley, Yulia Dementieva and Shahriar Shahriari. The authors would also like to thank Ben Allen and Christine Sample for conducting a scientific review of this study, as required by the Committee for the Protection of Human Subjects in Research at Emmanuel College.

\section{Appendix}

Table 4 Survey instrument with Likert-scale item stems

\begin{tabular}{|c|c|c|c|c|c|c|}
\hline \multicolumn{7}{|l|}{ TELL US ABOUT YOU } \\
\hline Gender & Male & \multicolumn{2}{|c|}{ Female } & & & \\
\hline Highest Degree Earned & Ph.D. & \multicolumn{2}{|l|}{ Ed.D } & Master's & Bachelor's & Other \\
\hline Area of Specialization & Mathematics & \multicolumn{2}{|c|}{$\begin{array}{l}\text { Applied } \\
\text { Mathematics }\end{array}$} & $\begin{array}{l}\text { Mathematics } \\
\text { Education }\end{array}$ & Other & \\
\hline Rank & $\begin{array}{l}\text { Full } \\
\text { Professor }\end{array}$ & $\begin{array}{l}\text { Associate } \\
\text { Professor }\end{array}$ & $\begin{array}{l}\text { Assistant } \\
\text { Professor }\end{array}$ & $\begin{array}{l}\text { Non-Tenure } \\
\text { Track } \\
\text { Instructor }\end{array}$ & $\begin{array}{l}\text { Teaching } \\
\text { Assistant } \\
\text { (TA) or } \\
\text { Associate }\end{array}$ & $\begin{array}{l}\text { Emeritus } \\
\text { Faculty }\end{array}$ \\
\hline $\begin{array}{l}\text { Years of Experience } \\
\text { Teaching in Higher } \\
\text { Education }\end{array}$ & $0-5$ & $5-1$ & & $10-20$ & $20-30$ & $\begin{array}{l}\text { More than } \\
30\end{array}$ \\
\hline $\begin{array}{l}\text { Years of Experience } \\
\text { Teaching Calculus in } \\
\text { Higher Education }\end{array}$ & $0-5$ & $5-1$ & & $10-20$ & $20-30$ & $\begin{array}{l}\text { More than } \\
30\end{array}$ \\
\hline
\end{tabular}


Table 4 (continued)

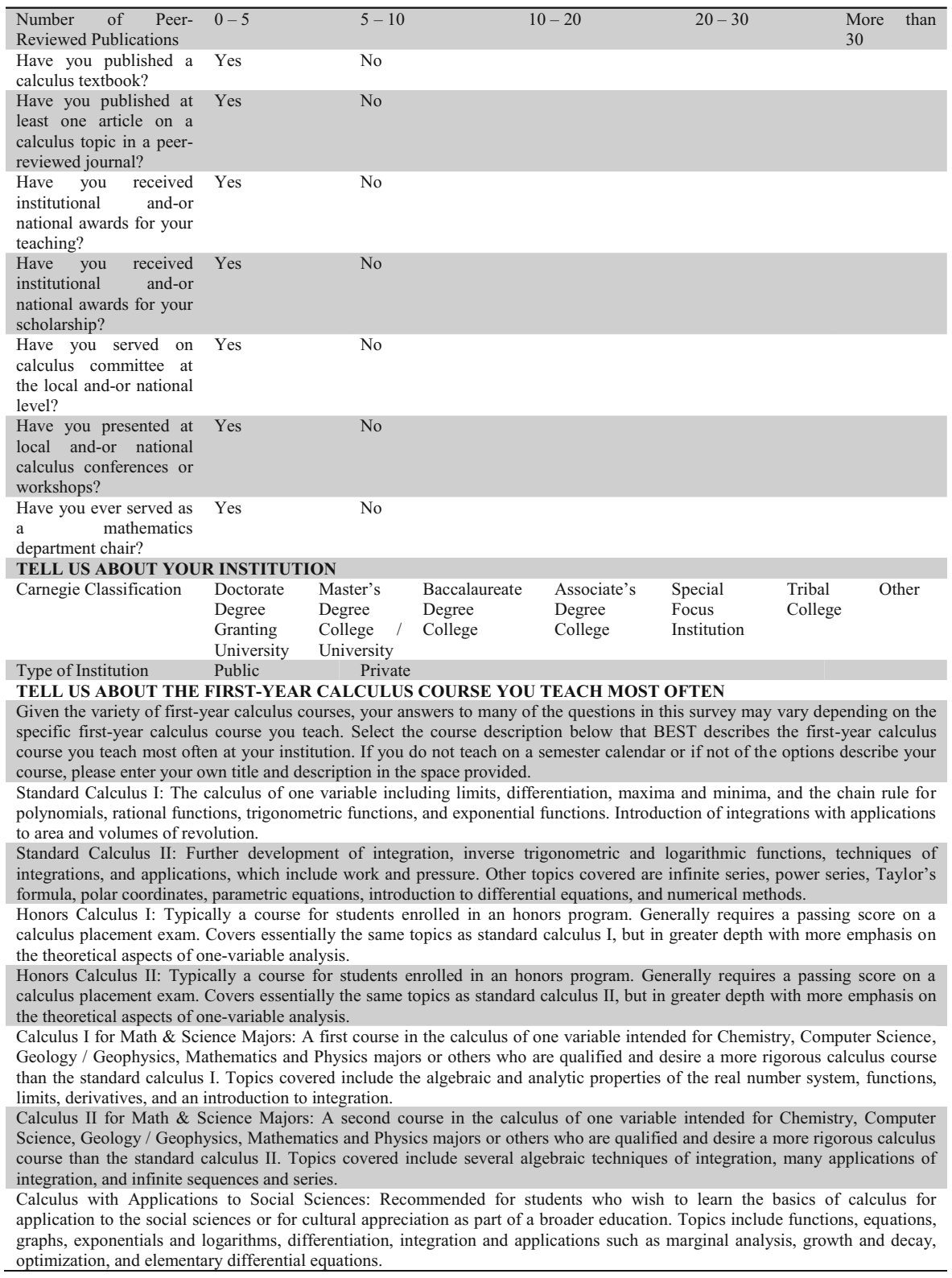




\section{Table 4 (continued)}

Calculus for Business and Economics: Fundamentals of analytic geometry and calculus; differential calculus, integral calculus, and selected applications of calculus; functions and managerial planning and their use in economics and business.

Other: (name and describe your calculus course if none of the above descriptions apply):

Do you have flexibility to include or exclude topics from your calculus syllabus? (open response)

OBJECTIVE QUESTIONS ${ }^{4}$

In my own teaching of the first-year calculus, ...

1. I emphasize approximation as a central concept of the calculus curriculum.

2. I use approximation as a unifying thread to connect many of the key ideas in the calculus curriculum.

3. I stress the importance of knowing how good an approximation is.

4. I discuss methods for calculating or estimating the error in an approximation.

5. I discuss the notion of acceptable levels of error in an approximation.

6. I provide opportunities for students to discriminate between various approximation techniques to identify which may work better in given situations.

7. I show how the slope of the tangent line can be approximated by slopes of secant lines where the function is differentiable ${ }^{5}$

8. I further explain that the error in that approximation (i.e., the difference between the slope of the tangent line and the slope of the secant line) can be made smaller than any predetermined bound.

9. I emphasize approximation of functions as a main theme of the calculus.

10. I discuss techniques for locally approximating differentiable functions with linear functions (i.e., linearization).

11. I discuss reasons for studying power series.

12. I demonstrate how power series can be used to approximate ${ }^{6}$ the values of complicated functions (e.g., functions for which an antiderivative is not easily calculated; functions whose values cannot be calculated solely by arithmetic operations; etc.).

13. I emphasize that - under suitable assumptions - the partial sum of a power series represents an approximation of a function at a point and within the interval of convergence this approximation can be made as accurate as possible by increasing the number of terms in the partial sum.

14. I demonstrate how to estimate the error term to evaluate how good a Taylor polynomial approximation is.

15. I demonstrate how to use the error term for Taylor polynomials to determine how many terms of a power series are sufficient to guarantee that an approximation has a given accuracy.

16. I discuss techniques for approximating definite ${ }^{7}$ integrals.

17. I use Riemann sums to discuss estimating the value of a definite integral.

18. I show how to use definite integrals to approximate a finite or infinite sum

19. I demonstrate how to quantify the error associated with an approximation of a definite integral.

20. I share examples of definite integrals that are best approximated numerically because the antiderivative of a function is hard or impossible to determine.

OPEN -ENDED QUESTIONS

21. Do you agree or disagree that the concept of approximation is important to student understanding of the first-year calculus? Please explain your response.

22. In what ways and to what extent do you use technology to promote student understanding of approximation in the first-year calculus?

${ }^{4}$ All item stems used a 5-point Likert Scale with $1=$ Strongly Disagree, $2=$ Disagree, $3=$ Neutral, $4=$ Agree and 5 = Strongly Agree. Each item stem was also followed by an open textbox for the optional explanation or qualification of the item stem response selected. Those textboxes have been omitted here, given space limitations.

5 The phrase "where the function is differentiable" has been added here for clarity; however, it was not included in this item stem during data collection.

6 The word "approximate" has been substituted here for clarity; however, the word "calculate" appeared in this item stem during data collection.

${ }^{7}$ The word "definite" has been added here for clarity; however, it was not included in this item stem during data collection.

\section{References}

Asiala, M., Cottrill, J., Dubinsky, E., \& Schwingendorf, K. E. (1997). The development of students' graphical understanding of the derivative. The Journal of Mathematical Behavior, 16(4), 399431.

Baroody, A. J., Feil, Y., \& Johnson, A. R. (2007). An alternative reconceptualization of procedural and conceptual knowledge. Journal for Research in Mathematics Education, 38(2), 115-131.

Berry, J. S., \& Nyman, M. A. (2003). Promoting students' graphical understanding of the calculus. The Journal of Mathematical Behavior, 22, 481-497.

Bressoud, D. M., Carlson, M. P., Mesa, V., \& Rasmussen, C. (2013). The calculus student: insights from the Mathematical Association of America national study. International Journal of Mathematical Education in Science and Technology, 44(5), 685-698. doi:10.1080/0020739X.2013.798874. 
Chai, J., Friedler, L. M., Wolff, E. F., Li, J., \& Rhea, K. (2015). A cross-national study of calculus. International Journal of Mathematical Education in Science and Technology, 46(4), 481-494. doi:10. 1080/0020739X.2014.990531.

College Board, The. (2015). Annual AP program participation. Retrieved from http://research.collegeboard. org/programs/ap/data/participation/ap-2014.

Czocher, J. A., Tague, J., \& Baker, G. (2013a). Coherence from calculus to differential equations. In S. Brown, G. Karakok, K. H. Roh, \& M. Oehrtman (Eds.), Proceedings of the 16th Annual Conference on Research in Undergraduate Mathematics Education: Vol. 2, Denver, CO.

Czocher, J. A., Tague, J., \& Baker, G. (2013b). Where does calculus go? An investigation of how calculus ideas are used in later coursework. International Journal of Mathematical Education in Science and Technology, 44(5), 673-684. doi:10.1080/0020739X.2013.780215.

Dorier, J. (1995). Meta level in the teaching of unifying and generalizing concepts in mathematics. Educational Studies in Mathematics, 29, 175-197.

Dray, T., \& Manogue, C. (2010). Putting differentials back into calculus. The College Mathematics Journal, 41(2), 90-100.

Epstein, J. (2013). The calculus concept inventory: Measurement of the effect of teaching methodology in mathematics. Notices of the AMS, 60(8). Retrieved from: http:/www.ams.org/notices/201308/rnoti-p1018.pdf.

Ferrini-Mundy, J., \& Graham, K. (1994). Research in calculus learning: Understanding of limits, derivatives, and integrals. In J. Kaput \& E. Dubinsky (Eds.), Research Issues in Undergraduate Mathematics Learning, (MAA Notes \#33, pp. 29-45). Washington, D.C.: Mathematical Association of America.

Galbraith, P., \& Haines, C. (2000). Conceptual mis(understandings) of beginning undergraduates. International Journal of Mathematical Education in Science and Technology, 31(5), 651-678.

Gordon, S. P. (1993). Calculus must evolve. Primus, 3(1), 11-18.

Gordon, S. P. (2011). A classroom note on: building on errors in numerical integration. Mathematics and Computer Education, 45(2), 148-156.

Gordon, S. P. (2012). Some surprising errors in numerical differentiation. Primus, 22(6), 437-450.

Gravemeijer, K., \& Doorman, M. (1999). Context problems in realistic mathematics education: a calculus course as an example. Educational Studies in Mathematics, 39, 111-129.

Hathaway, R. J. (2008). A simple acronym for doing calculus: CAL. Primus, 18(6), 542-545.

Heim, B., Rupp, F., Viet, N., Stockhausen, P. V., Gallenkämper, J., \& Kreuzer, J. (2015). Driving studentcentered calculus: results of a comprehensive case study for Kaizen learning in the Sultanate of Oman. International Journal of Mathematical Education in Science and Technology, 46(3), 354-369. doi:10. 1080/0020739X.2014.979897.

Hiebert, J., \& Lefevre, P. (1987). Conceptual and procedural knowledge in mathematics: An introductory analysis. In J. Hiebert (Ed.), Conceptual and procedural knowledge: The case of mathematics (pp. 1-27). Hillsdale: Erlbaum.

Hilbert, S., Schwartz, D. D., Seltzer, S., Maceli, J., \& Robinson, E. (2010). Calculus: An active approach with projects. Washington, D.C.: MAA.

Jungić, V., \& Mulholland, J. (2014). Is close enough good enough? Reflections on the use of technology in teaching calculus. International Journal of Mathematical Education in Science and Technology, 45(7), 1075-1084. doi:10.1080/0020739X.2014.892166.

Kannemeyer, L. (2005). Reference framework for describing and assessing students' understanding in the first year calculus. International Journal of Mathematical Education in Science and Technology, 36(2-3), 271-287.

Keynes, H. B. (1991). The calculus reform movement: some views from the outside. Primus, 1(4), 359-367.

Klopfenstein, K., \& Thomas, K. M. (2009). The link between Advanced Placement experience and early college success. Southern Economic Journal, 75(3), 873-891.

Kortendick, O. \& Fischer, M. (1996). Comparative classifications of ethnographic data: Constructing the outline of cultural materials. CSAC Studies in Anthropology, 11. Retrieved from http://ucy.ukc.ac.uk/ CSACSIA/Vol14/Papers/Kortendick/OCMPaper/OCMPaper_1.html\#H1.

Lang, X. (1999). CAI and the reform of mathematics education in China. International Journal of Mathematical Education in Science and Technology, 30(3), 399-404.

Mahir, N. (2009). Conceptual and procedural performance of undergraduate students in integration. International Journal of Mathematical Education in Science and Technology, 40(2), 201-211.

Martin, J. (2013). Differences between experts' and students' conceptual images of the mathematical structure of Taylor series convergence. Educational Studies in Mathematics, 82, 267-283.

Oehrtman, M. (2004). Approximation as a foundation for understanding limit concepts. In D. McDougall \& J. Ross (Eds.), Proceedings of the 26th annual meeting of the North American chapter of the International Group for the Psychology of Mathematics Education. Toronto: University of Toronto, (1), 95-102. 
Oehrtman, M. (2008). Layers of abstraction: Theory and design for the instruction of limit concepts. In M. P. Carlson \& C. Rasmussen (Eds.), Making the Connection: Research and Teaching in Undergraduate Mathematics (MAA Notes \#73, pp. 65-80). Washington, D.C.: MAA.

Oehrtman, M. (2009). Collapsing dimensions, physical limitation, and other student metaphors for limit concepts. Journal for Research in Mathematics Education, 40(4), 427-459.

Oehrtman, M., Carlson, M., \& Thompson, P. (2008). Foundational reasoning abilities that promote coherence in students' function understanding. In M. Carlson, \& C. Rasmussen (Eds.), Making the connection: Research and teaching in undergraduate mathematics education (MAA Notes \#73, pp. 27-42). Washington, D.C.: MAA.

Oehrtman, M., Swinyard, C., \& Martin, J. (2014). Problems and solutions in students' reinvention of a definition for sequence convergence. The Journal of Mathematical Behavior, 33, 131-148.

Oerhtman, M., \& Martin, J. (2015). About CLEAR calculus. Retrieved from: http://clearcalculus.okstate.edu/ about-clear-calculus.

Porter, M. K., \& Masingila, J. O. (2000). Examining the effects of writing on conceptual and procedural knowledge in calculus. Educational Studies in Mathematics, 42, 165-177.

Ramsey, J. L. (1992). Towards an expanded epistemology for approximations. PSA: Proceedings of the Biennial Meeting of the Philosophy of Science Association, 154-164.

Rasmussen, C., Marrongelle, K., \& Borba, M. C. (2014). Research on calculus: what do we know and where do we need to go? ZDM - The International Journal on Mathematics Education, 46, 507-515.

Rietz, H. L. (1919). On the teaching of the first course in calculus. The American Mathematical Monthly, 26(8), 341-344.

Riggle, T. A. (1968). The vector space as a unifying concept in school mathematics. Dissertation Abstracts International, (UMI No. 6815374).

Roberts, W. (1998). Calculus in the core. In J.A. Dossey (Ed.), Confronting the core curriculum: Considering change in the undergraduate mathematics major (MAA Notes \#45) Washington, D.C.: MAA.

Schoenfeld, A. (1988). When good teaching leads to bad results: the disasters of "well taught" mathematics courses. Educational Psychologist, 23(2), 145-166.

Sealey, V. (2014). A framework for characterizing student understanding of Riemann sums and definite integrals. The Journal of Mathematical Behavior, 33, 230-245.

Sealey, V., \& Oehrtman, M. (2005). Student understanding of accumulation and Riemann sums. In G. Llyod, M. Wilkins, \& S. Behm (Eds.), Proceedings of the Twenty-Seventh Annual Meeting of the North American Chapter of the International group for the Psychology of Mathematics Education [CDROM]. Eugene: All Academic.

Shahriari, S. (2006). Approximately calculus. Providence: American Mathematical Society.

Shoenthal, D. (2014). Fourier series as a unifying topic in Calculus II. Primus, 24(4), 294-300.

Sierpinska, A. (1987). Humanities students and epistemological obstacles related to limits. Educational Studies in Mathematics, 18, 371-397.

Sierpinska, A. (1990). Some remarks on understanding in mathematics. For the Sake of Learning Mathematics - An International Journal of Mathematics Education, 10, 24-36.

Sofronas, K. S., DeFranco, T. C., Vinsonhaler, C., Gorgievski, N., Schroeder, L., \& Hamelin, C. (2011). What does it mean to understand the first-year calculus? Perspectives of 24 experts. The Journal of Mathematical Behavior, 30(2), 131-148.

Strang, G. (1987). Calculus for a purpose. In L. A. Steen (Ed.), Calculus for a new century: A pump, not a filter (p. 54). Washington, D.C.: Mathematical Association of America.

Swinyard, C. (2011). Reinventing the formal definition of limit: the case of Amy and Mike. The Journal of Mathematical Behavior, 30, 93-114.

Thompson, P. W. (1985). Experience, problem solving, and learning mathematics: Considerations in developing mathematics curricula. In E. A. Silver (Ed.), Teaching and learning mathematical problem solving: Multiple research perspectives (pp. 189-243). Hillsdale: Erlbaum.

Yang, Y., \& Gordon, S. (2008). Finding the best linear approximation to a function. Mathematics and Computer Education, 42(2), 95-108.

Yerushalmy, M., \& Schwartz, J. J. (1999). A procedural approach to exploration in calculus. International Journal of Mathematical Education in Science and Technology, 30(6), 903-914.

Zandieh, M. J. (2000). A theoretical framework for analyzing student understanding of the concept of derivative. In E. Dubinsky, A. H. Schoenfeld, \& J. Kaput (Eds.), Research in collegiate mathematics education IV (Vol. 8, pp. 103-127). Providence: AMS and MAA.

Zorn, P. (1991). Discontent in San Antonio. UME Trends, 3(1), 1-4. 